\title{
The Effect of a Group Counseling Program in Training in Communication Skills to Improve Self-Esteem and Adjustment in Male Children to Divorced Parents
}

\author{
d-Nagham Mohammad Abu-Albasal ${ }^{1, *}$ \\ ${ }^{1}$ Princess Rahma-College, Al-Balqa- Applied University, Alsalt, Jordan \\ *Correspondence: Princess Rahma-College, Al-Balqa- Applied University, Alsalt, Jordan. \\ E-mail: mohammedolimat29@yahoo.com
}

Received: July 25, 2014 Accepted: August 26, 2014 Published: December 18, 2015

doi:10.5296/ije.v6i4.8761ＵRL: http://dx.doi.org/10.5296/ije.v6i4.8761

\begin{abstract}
This study aimed to measure the impact of training on communication skills to improve self-esteem and adapt children to divorced parents.

The study sample consisted of (12) participants in mail children to divorced parents in the eighth grade in the school of Directorate of Education - Balqa Governorate for the scholastic year calendar 2012-2013.

The study sample was divided into two groups:- first an experimental group of (6) students were subjected to collective guidance program on training for communication skills consisting of eight sessions. Second a control group consisting of (6) students were not exposed to any address.

The participants in both groups answered a scale of self-esteem and adjustment scale before and after the application of the program. Results indicated the effectiveness of training on communication skills program where appeared statistically significant differences in favor of the experimental group compared to the control group in self-esteem and in the level of adaption.
\end{abstract}

Keywords: counseling, communication skills, self-esteem, adjustment, divorced parents 


\section{Introduction}

Divorce is a negative social phenomenon which effect or damage family life, one of the most important aspects of family disintegration, divorce leaves substantial effects on children hinder the adaption of social and psychological, as the deprivation of parental care harms sons and effect the adaption of social and hamper growth psychological, as it leaves and impact clear on academic achievement (Sabeq 1998 page 278).

Also divorce is a strong chock to the children especially during the first year of such divorce. They suffer psychological and family situations. Loss caring parented them and deteriorating health and landing morale face at the tears and despair more than ever rebel against the authority of their parents. The absence of their father they have a concern (Omar, 1994). It is undoubtedly a sad and disturbing experience for children. Children to divorced parents suffer from disorders that require presentation on mortal clinic. The children are showing difficulties in the activity to play, and in their relationships with others, because the child in this case does not suffer only from the pressure, it is the same labor and in order to adapt and compatibility with this pressure, but it is also exposed to the father suffers from pressure as well, and he has to adapt and complies with this father at his critical juncture (Issawi, 1993), And indicate the study carried out by the (Amato, 2000) that most children and adolescents who are exposed to experience divorce to parents or a second marriage to apparent suffering from disorders exposed during this period to the ongoing conflict and stress as a result of changes that occur due to differences on the way of treating him by a parent or his departure pensions due to divorce if the father has gone, family will experience the loss of a source of income if not working mother.

The different reactions of the children to their parents, including:

i-The age of the child when parents divorced, reactions of children about divorce differ from the reactions of teenagers (Burns, 1997).

ii-Sex of child (Kail, 1998) it is better to live girls within the confines of their mothers while the boys with their fathers.

iii- The presence of social support to children:- children are rookies in the houses led by the mother and grandmother were their best of the situation of children rookies in homes with a stepmother or stepfather or even with only one parent (Steinberg, 1996).

iv-The nature of the child:- One of the factors that affect the child's reactions about divorce is the child's nature and personality, and the child's ability, and to adapt to circumstances (Smith, 1999).

v-Attitudes and behavior to divorced parents towards their children:- (Berns, 1997) mention that the parents are aware preparing for divorce and or making their sons with them, all causes and respect each other. 


\section{The importance of the study}

The importance of the study of being involved with a group of male to parents divorced who are exposed to negative effects as a result of divorce children faced to experience the separation of parents affects them in different ways, it seems that it is difficult to adapt to social and psychological, which generates a divorce violent reactions when children in various aspects, child feels deprivation affects important aspects of his life and often this is accompanied by a sense of sadness and pain that appears in the form of crying and low self-esteem and difficulty concentrating in his school, leading to underachievement.

The courts indicate a rise in the divorce rate and the rise makes us think of the importance of the presence of specialized centers for guidance and family counseling services and marital status as well as the importance of providing counseling services to students.

\section{Problem of the study}

The application of collective program guide on a group of males to divorced parents may contribute to the mitigation of the effect of divorce, also contributes to the improvement of their psychological adjustment which increases the appreciation for themselves.

\section{Objective of the study}

The present study aims to alleviate the impact of the divorce on a group of males to divorced parents through the application of collective guidance program for training in communication skills.

\section{Procedural definitions}

\subsection{Group counseling}

The guidance of individuals whole suffer from the same problem in small groups ranging from five to seven members to help them detect and analyze problems and to understand themselves and accept others and preferred to be a homogeneous group in terms of age, and the problems faced by the members of the group. The purpose of the collective guidance is to create a safe environment for children to enable them to speak boldly and freedom of interpretation thereof felt toward his parents separated (Smith, 1999). For the purposes of this study has been use collectivist guidance program on communication skills developed by the (girls, 2004).

\subsection{Communication skills}

Mean the skill of active listening and re-drafting, and the expression of feelings, empathy, summarizing, feedback, wonder, and termination. These skills can be acquired through the 
learning (Corey, 1994). For the purpose of this study has been used counseling program developed by the Assembly (Girls, 2004) for training in communication skills

\subsection{Self-esteem}

Is the value that gives the individual's self-perceived if the individual is satisfied with the same receptive them and feel their value, the appreciation of the same will be high, and if seen for itself negatively, the appreciation of the same will be low (Rice, 1995). In this study, the self-esteem is measured primarily obtained by participating on a scale estimate self-developed by the (Al-Qsoos, 1985).

\subsection{Adjustment}

Is the process by which the individual seeks to change so that it can adapt to the requirements of the environment, this change may be internally or externally, through which. The individual seeks to deal with the problems and challenges and pressure they are facing, adjustment is measured in this study is primarily obtained by participating on a scale developed by adaptation (Gabriel, 1996).

\section{Questions of the study and its hypotheses}

This study attempts to answer the following question:-

What the effect of collective guidance in training in communication skills to improve self-esteem and adjustment among a sample to male parents divorced?

This study is trying to verify the following assumptions:-

i- There are no statistically significant differences (at the level of a $\geq 0.05$ ) in self-esteem among males to divorced parents in the experimental group that received training on communication skills and the control group.

ii- There are no statistically significant differences (at the level of a $\geq 0.05$ ) in the psychological adjustment between males to divorced parents in the experimental group that received training on communication skills and the control group.

\section{Previous studies}

Can be referred to the lack of studies that have addressed the issue of children to divorced parents training mentoring program on communication skills, but there are many students that dealt with training within the collective guidance program for special categories (such as battered women, abused children, and events...) on communication skills. The following are some studies related to the subject.

In a study conducted by the (Girls, 2004), aimed at measuring the impact of training on communication skills of battered women, and reducing domestic violence. Study sample consisted of (47) post showed a measure of domestic violence who have responded to their 
daughters having the highest degree of domestic violence in their homes, has been dividing the sample into three groups, two experimental groups and a control group. Where undergone posts in the first experimental group and their number (8) solo program guide posts in the second experimental group and their number (10) solo program guide collectivist about communication skills, while not exposed posts in the control group and their number (13) post any treatment.

The results indicated the effectiveness of the training program on communication skills, problem solving, where appeared statistically significant differences in favor of the experimental groups compared to the control group in self-esteem and level adjustment in the level of domestic violence while it did not show significant differences between the two groups.

(Ahmad, 2004) also held study of the effectiveness of the program guide collectively to improve the psychological adjustment and self-concept children abused, study aimed to investigate the effectiveness of the program guide collectively to improve the compatibility and self-concept among a sample study, which considered of (30) children ages ((12-17 years). Divided the sample randomly into two groups, experimental and control group, the rate of (15) children in each group, received the experimental group trained through the program, consisting of ten sessions, while not under the control group of the program extension, and adapted a researcher at the program on self-affirmation and immunization against tension and relaxation. The results of the study showed differences between the two groups in favor of the experimental group and the program in improving psychological adjustment and self concept.

In the study conducted by (Mahameed, 2003), aimed to detect effectiveness of collective guidance, (Jashtalti) the program to improve the level of communication among a sample of juvenile delinquents. The study sample consisted of (28) event offenders from the juvenile delinquents who are at the center of Muhammad bin Qasem in the city of Irbid, has been distributed into two groups, the first experimental group consisted of (14) event received (Jashtalti) training program to improve the level of communications for (12) weeks two sessions every week, and the second control group members did not receive any counseling program.

The results indicated that there were statistically significant differences in the level of communications and the fields for the benefit of members of the experimental group who have been subjected to a training program.

Also (Hall, 1991) held a study aimed to investigate the effect of the program guide collectivist to modify the center control among a sample of people with families dismantled, has been the goal of the program during its sessions to build self-confidence and communication skills and leadership skills. Results showed statistically significant differences in favor of the experimental group to modify the settings for the center have since become the center with internal control more than the control group that did not undergo counseling program. 
in a study of (Jupp \& Griffiths, 1991) to identify the effectiveness of the program guide in order to raise self-concept has been the comparison programs for training in social skills for (30), a teenager suffering from shyness and social isolation, use one of the programs discussion and activities in the guidance collective, while use the second program role playing style.

The results showed a statistically significant differences and improvement in self-concept in the group that received training in social skills based on the role playing more than the traditional group (control group), which relied on the discussion and activities. :-

\section{Methodology and research methods}

The study sample consists of (12) participants from eighth grade students have been regrouped from male school in the Directorate of Education - Balqa Governorate for the scholastic year calendar (2012-2013) from the male to parents divorced who have agreed to participate the study.

Participating students were selected with intention for males to parents who divorced and then participants were distributed randomly into two groups, an experimental group number of its members are (6) and control group members consisted of (6) participants.

\section{Tools of study}

\subsection{Measure of self-esteem:- (Appendix 1)}

The researcher used the self-esteem scale developed by the (Al-Qsoos, 1985), the scale consisted of thirty-eight paragraph measure the following aspects:-

i-The mental side:- Estimation of the individual to his or her abilities.

ii-The social aspect:- Determination of the individual's relationship with others.

The scale consists of thirty-eight paragraph. Responding to the paragraphs of the scale estimate co extent applicable to him the content of the paragraph on a scale of five points, which indicates the number (5) to a very high degree of self-esteem, while the number indicates (1) to very low appreciation of the co-itself.

Ranging from the total score on scale of (38-190) degree, which reflect the degree (38) with a low estimate, and the upper class (190), they reflect the high estimate.

\subsection{Scale veracity}

The extract the sincerity of the scale, (Al-Qsoos, 1985) extracted the truth in two ways: one approved construction where the building measure in the light of theory and research on the subject of self-esteem, and based on the logical analyses of the components of this personal trait,. The other is the honesty predictive, were considered Al-Qsoos studies as a basis for 
choose honesty predictive for scale. Where I assumed that achieving empirical hypotheses on factors proved previous studies linked to self-esteem proof of his sincerity.

\subsection{The stability of the scale}

With regard to consistently measure, Al-Qsoos calculated the half reliability coefficient of the test sample of fifty female students from students who participated in the study. It turn out that the test had an acceptable degree of stability (0.92) to justify its use in this study.

\section{1- Measure of psychological adjustment:-}

The researcher used measure of psychological adjustment, developed by (Gabriel, 1996). The scale consists of forty paragraphs, each dimension of such paragraph measured through ten paragraphs. The paragraphs included the following dimensions, personal dimension, and the emotional dimension, the dimension of family and social dimension.

Paragraphs scale should be corrected by Likert way from one to five, the given answer should be (always) 5 degrees, the answer (most of time) given 4 degrees, some answer given 3 degrees, and given to answer (little) 2 degrees, but the answer (never) are given 1 degree. The grading is reversed in the case of paragraphs are negative paragraphs, positive scores are collected as they are.

\subsection{Scale veracity}

Gabriel reached a certified scale in two ways:

The first way to extract honesty rationale for the measure, submitting it to ten arbitrators of specialists in education and psychology, where they were asked to show the validity of the phrase to measure for what purpose of the phrase has been put for, when they have been informed of the dimensions of the scale, and then where asked to indicate the extent and clarity of phrase and propose the necessary adjustments. Agreement has been adapting of a standard of eight arbitrators on the validity of the paragraph and clarity to remain within the scale.

The second way was to get the truth of the scale by comparing the performance on the scale in the two extremist groups in the characteristics that put the scale to be measured, was then a sample of sixty students, half of them are in positive adjustment, the other half are in negative adjustment. When the scale has been applying on the two groups, it was found that the measure is able to distinguish between them.

To extract the stability of the scale, Gabriel calculated the reliability co-efficient scale repatriation way, through the re-application of the scale after twelve days on a sample of forty students from the tenth graders and the first secondary. Reliability coefficient has reached the total score (0.94). This suggests that the scale has an acceptable degree of stability to justify its use in this study. 


\section{Communication skills program}

The researcher had used the collective guidance on communication skills developed by the (Banat, 2004). The program considered of (8) sessions, an hour per session, with the aim of helping participants to better adapt to put the separation of the parents, and improve the self-esteem of participants by providing them with communication skills to help them behave better.

At the first meeting between the group members, the researcher introduced herself to the participants. Participants has the same definitions then they repeat the names of other participants shared in the program, after that they discussed what is expected and what can be achieved through the program.

In the second session, participants were trained on the skills of present behavior that include active listener, and visual contact with other party, then sit in a way another that he found him interest. This has been done by modeling those behaviors and use style role playing and training participants to pay attention to the person speaker given to him and do the gestures feel the other party interest, such as shake the head, sit put stand forward, and not the province with an effort to understand what the speaker is saying.

It was at the third meeting, training participants to express their feelings in a way socially acceptable, so that has been used modeling and role playing to express positive and negative feelings as the show emotions contribute to achieving harmony between what the individual and feel to it as to show positive feelings about what other people are doing at us over their behavior and the expression of negative emotion due to actions of others towards us reduces their behavior such actions in the future.

In forth session, have been discussing the skill of empathy on that individual's ability to understand the other party (thoughts and feelings), thus to gain understanding through active listening with this show, understanding by responding to individual. It has been clarifying how to show empathy with other party through role playing and modeling empathize with others by the participants.

At the fifth meeting, the message it was discussed I am (self-disclosure) which is the way to take responsibility for ourselves and figuring out what in us. The message you are, and to clarify the differences between them, and to distinguish the impact of each other, then participants were trained on the use of those letters and ask examples during the session on those messages.

Including the sixth meeting, to discuss the response of confirmed and unconfirmed we say something in uncertain, or may interact much more we either leave the situation goes without saying that something is uncertain or may interact much more or understand other person without paying attention to our behavior (aggressive) through discussion to participants in the sense of the term self-affirmation and to differentiate between responding and unconfirmed or aggressive response. 
In the seventh session, it has been training the participants to respond in a certain manner through the use of role playing style. Practice communication skills held during this meeting which had been discussed during the previous sessions.

In the eighth and final session, it was indicative program evaluation and discussed what has been achieved and the degree to which participants apply to communication skills that have been rehearsed.

\section{Study procedures}

Sample of (12) male students from eight grades in the School of Directorate of Education for the scholastic year calendar (2012-2013) have been selected to divorced parents, after obtaining the consent of the students to participate in the program indicative, were distributed randomly in two groups; the experimental group were trained participants to communication skills, and control group did not receive any training.

After that, individual interviews were made to the participants in the study, during which the definition program and obtaining the approval to join the train, and recognize the conditions of the participants. After that standards were applied study participants (a measure of self-esteem and adjustment scale) before starting the application indicative program.

Was then start applying the collective extension program, which aimed to develop communication skills of the participants in the experimental group, numbering six participants, which consists of eight sessions, one hour per each session.

After the completion of the application containing the extension program participants training on communication skills, the researcher reapply study metrics on the sample, to measure the level of adaptation and self-esteem of the participants to compare the scores before succumbing to the training program and beyond.

\section{Results}

The present study aimed to identify the impact of the collective guidance program for training in communication skills. Improve self-esteem and psychological adjustment among a sample of male to parents divorced. It was initially extract test results (T) to examine the differences between the averages of the self-esteem of the experimental and control groups on the pretest examine. It is clear that the both groups unequal and Table number (1) shows the results.

Table 1. The result $(\mathrm{T})$ to examine differences between the means of self-esteem for both experimental and control groups on the pretest

\begin{tabular}{lccccccc}
\hline Group & Number & Average & $\begin{array}{c}\text { Standard } \\
\text { deviation }\end{array}$ & $\begin{array}{c}\text { Value } \\
(\mathrm{T})\end{array}$ & $\begin{array}{c}\text { Freedom } \\
\text { average }\end{array}$ & Statistical & $\begin{array}{c}\text { Statistical } \\
\text { significance }\end{array}$ \\
\hline Experimental & 6 & 124.16 & 28.5 & 0.025 & 10 & 0.5 & 0.98 \\
Control & 6 & 124.66 & 38.5 & 0.025 & 9.2 & & 0.98 \\
\hline
\end{tabular}


Illustrate by looking at the table that the two groups are equal as the arithmetic mean of the experimental group amounted to 124.16, as arithmetic average of the control group 124.66 and this refers to equal the arithmetic mean of the two groups. With regard to the standard deviation has reached the experimental group 28.5, and the standard deviation of the control group 38.5. Extract value (T) it has been shown that the two groups are equal.

To examine the first hypothesis, which states that there were no statistically significant differences at the level of $(a \geq 05)$ the level of self-esteem among the participants in the experimental group and the control group.

Average and standard deviations for the two experimental and control groups has been extracted after the submission of treatment (application program guide collective communication skills) on a scale of self-esteem results were as shown in table (2).

Table 2. Average and standard deviations of the experimental group and the control group on the post-test (self-esteem)

\begin{tabular}{lcc}
\hline Group & Arithmetic average & Standard deviation \\
\hline Experimental & 138.83 & 4.16 \\
Control & 123.50 & 4.03 \\
\hline
\end{tabular}

It is clear from table (2) that there are differences in there are differences in the arithmetical average and standard deviations of the two groups on the post test where the arithmetic mean of the experimental group (138.83), while the arithmetic mean of the control group (123.50), as was the standards deviation of the experimental group (4.16), while the standard deviation of the control group (4.03).

To examine whether these differences were statistically significant in the performance of the sample on the post-test (a measure of self-esteem) due to the variable group for the experimental group, were extracted analysis of covariance and Table number (3) illustrates this.

Table 3. Covariance analyses results to significant differences between the averages of experimental and control groups on the post-test (a measure of self-esteem)

\begin{tabular}{lccccc}
\hline Sources of & Total square & $\begin{array}{c}\text { Degree of } \\
\text { freedom }\end{array}$ & $\begin{array}{c}\text { Average } \\
\text { square }\end{array}$ & $\begin{array}{c}\text { Value } \\
(\mathrm{V})\end{array}$ & $\begin{array}{c}\text { Statistical } \\
\text { significant }\end{array}$ \\
\hline Treatment group & 704.48 & 1 & 704.48 & 38.47 & 0.000 \\
Pretest (variable associated) & 3.53 & 1 & 3.53 & 0.193 & 0.671 \\
Error & 164.80 & 9 & 18.31 & & \\
Total & 20733.0 & 12 & & & \\
\hline
\end{tabular}


As shown in Table number (3) the presence of statistically significant differences in the performance of the sample on the post-test (a measure of self-esteem) is attributable to a variable set for the experimental group, as the value of (V) 38.47 a value statistically significant at the level of $(a \geq 0.05)$. with reference to the table arithmetic averages note that there are differences in favor of the experimental group of the participants in the collective extension program on communication skills, where the higher the level of self-esteem of the participants in the experimental group is statistically significant.

As can be seen from the table also no statistically significance differences in the performance of the sample on the post test (self-esteem) is attributable to the impact of pre-test and this refers to is not affected by the performance of the sample in the experimental and control groups on the pretest performance on the post-test.

This can be attributed to the collective extension program, focused on communication skills where participants that the possession of communication skills is a source of power that supports their appreciation for themselves, through the application of these skills while dealing with the pressure they face and conflict as a result of parental divorce.

For the second hypothesis, which states that:-

No statistically significant differences at the level of $(a \geq 0.05)$ in the level of adaptation of the male to divorced parents in the experimental group that received training on communication skills and the control group.

To examine this hypothesis has been extracted average and standard deviations of experimental and control groups, after the submission of treatment (collective application program guide for training on communication skills) on a scale adjustment results were as shown in

Table 4. Average and standard deviations of experimental and control groups on the post-test (adaptation)

\begin{tabular}{lll}
\hline Group & Arithmetic average & Standard deviation \\
\hline Experimental & 138.33 & 6.121 \\
Control & 124.33 & 2.65 \\
\hline
\end{tabular}

Shown Table number (4) that there are differences in the averages and standard deviations of the experimental and control groups, where the arithmetic mean of the experimental group (138.33), while the arithmetic mean of the control group (124.33), with a standard deviation of the experimental group (6.121) while the standard deviation of the control group (2.65) to examine whether these differences were statistically significant in the performance of the sample on the post-test (measure of adaptation) attributable to the experimental group variable analyses of covariance. 


\section{Mll Macrothink}

Table 5. Covariance analysis results to significant differences between the arithmetic averages of two experimental and control groups on the post-test (a measure of adaptation)

\begin{tabular}{lccccc}
\hline $\begin{array}{l}\text { Sources of } \\
\text { variation }\end{array}$ & Total square & $\begin{array}{c}\text { Degree of } \\
\text { freedom }\end{array}$ & $\begin{array}{c}\text { Average } \\
\text { square }\end{array}$ & Value (V) & $\begin{array}{c}\text { Statistical } \\
\text { significant }\end{array}$ \\
\hline $\begin{array}{l}\text { Group } \\
\text { treatment }\end{array}$ & 553.07 & 1 & 553.07 & 24.50 & 0.001 \\
$\begin{array}{l}\text { Pretest } \\
\text { (associated }\end{array}$ & 19.53 & 1 & 19.53 & 0.86 & 0.377 \\
$\begin{array}{l}\text { variable) } \\
\text { Error }\end{array}$ & 203.13 & 9 & 22.57 & & \\
Total & 207792.0 & 12 & & & \\
\hline
\end{tabular}

Shown in Table number (5) and the presence of statistically significant differences in the performance of the sample on the post test (adaptation) due to the variable group for the experimental group as the value of (V) 24.50 a statistically significant as the level (a $\geq$ 0.05 , this refers to the impact of the indicative program used to the train participants on communication skills in improving adaptability to sons of divorced parents.

As can be seen from the table there is no statistically significances as in the performance of the sample on the post-test (adaptation) attributed to the impact of pre-testing, and this refers to the lack of impact the performance of the sample in the experimental and control groups on the post-test.

Support the results of this study, the researchers confirmed that the communication skill training, help trainee to overcome adversity and to adapt better.

A counseling program collective included training on communication skills, where the participants proceed exercises and modeling, as well as provide a safe place, which includes acceptance of positive unconditional and listen effectively to understanding empathic, and provide social support all of this contributes to mitigate the effects left by the divorce on family members, including sons.

In light of the findings of the study can propose the following recommendations:

- Educate counselors on collective extension programs to train students in the school.

- To emphasize the seriousness of divorce to whole family members, and work to develop plans and programs especially male children to divorced parents and the other as husband and wife in an intensive outreach programs 


\section{References}

Ahmad Ahmad, Ata (2004). The effective of group counseling to adapt self-esteem and understanding themselves towards abused children. Al-Hashemia University - Zerka Jordan.

Al-Qsoos, Hind. (1985). Relationship between self-esteem and success prediction. Jordan University - Amman - Jordan.

Amoto, Paul. R. (2000). The consequences of divorce adults and children. Journal of Marriage and Family, 62(4), 1269-1287.

Banat, Suhaila. (2004). The effect of training of communication skills and solve problems to improve self-esteem and behave the battered women and reduce the family violence. Jordan University - Amman - Jordan.

Berns, Roberta. M. (1997). Child family school. Community Harcourt.

Brace college publishers United States of America: Pacific Grove, Brooks Cole.

Corey, G. (1994). Theory and practice of group counseling (4th ed). Pacific Grove. CA: Brooks/Cole.

Essawe Abdulrahman. (1993). Family psychological according to Islamic and scientific sight. Dar Al-nahda Alarabya - Bierut.

Jupp, J.J., \& Griffiths, M.D. (1991). Self-Concept changes in shy socially isolated addescents following social skills training emphasizing role play. Psychological Abstract, 78(1-6), 2222.

Hgshbeq, Alsayed. (1998). Feqh Alsunneh(2nd edition.). Dar al fath for distributing.

Gabreil, Musa. (1996). The relationship between control center and education and self-esteem for adolescence, studying, science educational MJ 23(2) Jordan University, Amman Jordan.

Kail. Robert. V. (1998). Children and Their development. Prentic Hall-Upper Saddle River.

Mahameed Fayez. (2003). Efective of Jashtalti guidance program for adapting communication and reduce the bad behavior towards sample of juvenile. Yarmouk University Irbid Jordan.

Omar, Maan Khalil (1994). Science of social family. Amman: Dar Alshorook.

Rice, F.P. (1995). Human development: A Life-span approach. New York: Macmillan Publishing Compaany, Inc.

Smith Heather. (1999). Children Feelings and Divorce. Free Association books-London.

Steinberg Laurance. (1996). Adolescence. M.C. Graw Hill. 


\section{Copyright Disclaimer}

Copyright reserved by the author(s).

This article is an open-access article distributed under the terms and conditions of the Creative Commons Attribution license (http://creativecommons.org/licenses/by/3.0/). 